\title{
Special Needs at Different Educational Levels: A Forecast of 2020
}

\author{
http://dx.doi.org/10.3991/ijet.v7i4.2168 \\ C. Karagiannidis ${ }^{1}$, C. Kouroupetroglou ${ }^{2}$ and A. Koumpis ${ }^{2}$ \\ ${ }^{1}$ University of Thessaly, Volos, Greece \\ ${ }^{2}$ ALTEC Software S.A., Thessaloniki, Greece
}

\begin{abstract}
This paper reports on the results of the eAccessibility 2020 study which was funded by the European Commission to explore and analyse the relationships between the emerging Information and Communications Technologies (ICT) landscape in the societal and economic context, and the development and provision of assistive technologies and eAccessibility within a perspective of the next 10 years. The methodology of the study included both desk research and direct contact with relevant actors through 2011 and 2012. The results of the study are summarised for different educational levels (from primary-school to post-university) and are presented in terms of core issues, which are the most important developments in the area that will concentrate research and development efforts; roadmaps, which are most probable elements of a future research agenda in the area; and potential scenarios, which are indicative and not necessarily representative examples of use cases that may appear in the field.
\end{abstract}

Index Terms—accessibility, future accessibility technologies, scenario development.

\section{INTRODUCTION}

At the World Education Forum [1] that took place in Dakar in 2000, 164 governments pledged to achieve "Education for All" (EFA) and identified six goals [2] to be met by 2015. UNESCO, which is the leading agency in that movement, focuses its activities on five key areas: policy dialogue, monitoring, advocacy, mobilization of funding and capacity development. Inclusive education covers a broad range of problems in accessing education such as children living in areas of conflict, cultural issues, gender issues, etc. Including children with disabilities in inclusive learning environments is just a part of it. However, the techniques and methods that can be used to include all children in education remain the same. To that direction UNESCO has already published a guide for teachers titled "Understanding and Responding to Children's Needs in Inclusive Classrooms" [3] where it explains various possible problems that a kid might have in a class due to a disability or various other chronic illnesses and offers a variety of possible solutions that the teacher might exploit in order to facilitate learning for those children. In another document titled "Changing Teaching Practices: using curriculum differentiation to respond to students' diversity" [4] UNESCO offers a more extensive guide on techniques for curriculum differentiation that can be employed by teachers to help them include all children in education. Effective policies and practices for inclusive education are also explained and presented in the article by Cor J.W. Meijer in 2010 [5].

In Europe, the European Agency for Development in Special Needs Education, which is an independent and self-governing organization established by EU member countries to act as a platform for collaboration in the field of special needs education, has published a series of documents on various issues of inclusive education. In the report "Inclusive education and classroom practices" [6] they refer to useful and successful practices that can be used to implement inclusive education in practice and in "Key Principles for Promoting Quality in Inclusive Education" [7] a set of recommendations is provided for policy makers. In another report titled "Inclusive Education and Classroom Practice in Secondary Education" [8] a set of practices to implement inclusive education in secondary schools is provided through case studies in 14 EU countries and the report "Assessment in Inclusive Settings - Key Issues for Policy and Practice" [9] focuses on practices of assessment that can be employed for inclusive education. Finally, the report "Special Needs Education Country Data 2010" [10] shows the current status in education of pupils in primary and secondary schools in EU countries. Inclusive education might be a goal for 2015 according to UNESCO but the report shows the current statues in practices followed in EU countries. Currently there are 3 kinds of settings for providing education to pupils with Special Education Needs (SEN). The first is through segregated special schools for pupils with SEN, the second is through segregated special classes in mainstream schools and the third is through classes with fully inclusive settings. The report reveals that there is a lot to be done to reach the level of full inclusive learning environments becoming the standard of providing education to students with SEN. Amongst the Europeans Agency reports though there is also a very interesting report titled "ICTs in education for people with disabilities" [11] presenting case studies of ICTs being used to facilitate inclusive education settings for people with disabilities.

In this context, the European Commission launched on 2010 a tender for the eAccessibility 2020 study with the following objectives (www.e-accessibility2020.eu):

- To conduct a validated analysis of the relationships between the emerging ICT landscape, the societal and economic context and the development and provision of assistive technologies (AT) and eAccessibility, building on a sound understanding of relevant trends and challenges. 
- To elaborate and discuss a series of hypothetical scenarios on the future evolution of AT and eAccessibility.

- To provide validated recommendations for research priorities and policy measures that are usable at European level.

The methodology was divided into 3 phases, as shown in Figure 1:

a) The Groundwork Phase, where the proposed methodology is further specified and refined, while data/info are gathered, organised and initially analysed in such way so as to facilitate search, retrieval and use in the following phases.

b) The Divergent Phase introduces the core creative activities of the study aiming to assess key trends and identify \& assess micro-trends and weak-signals. Initial scenarios are roughly drafted.

c) The Convergent Phase places in order the outcome of the Divergent phase, involves a more structured and consolidated approach towards scenario building, validation and final recommendations and conclusions.

The data were collected through a variety of methods, including:

- Desk research: The study team carried out deskresearch mainly in order to identify and assess data/info available through the internet and commercial databases.

- Direct contact with relevant actors (through meetings, interviews or workshops) to gather first-hand evidence and feedback on premises for and results from the analysis: A large number of interviews were conducted throughout the study lifetime, starting from the scoping session, data/info gathering, continuing with telephone and electronic communication with representatives of stakeholders and individual experts, face-to-face interactions during 2 study workshops, as well as during e-Accessibility relevant events.

- Socio-economic analysis, including quantitative analysis, according to appropriate research techniques, e.g. for economic modelling and scenario building: A number of different methods/techniques for socio-economic analysis were implemented during the study, including: Scenario Building, Impact assessment, Cluster Analysis, Associations Analysis, Social Network Analysis, DELPHI as well as quantitative forecasting methods (e.g. time series) to forecast trends such as demographics, market size, etc.

- Online exchanges with people knowledgeable about or interested in the topic, e.g. using the www.epractice.eu platform: Two ePractice communities were primarily targeted under the present study: the "eInclusion policy, analysis and practice" community which involves 143 Members, and the "eAccessibility practice, policy, monitoring and impact" community which hosts 98 Members. Two additional relevant communities which were involved were the 'Cities working on e-Inclusion' and 'SocioEconomic Impact Assessment of ICT for Ageing Well Solutions', which however are smaller and less active.

- Interaction with experts in the field of AT/ eAccessibility and, more generally, IT-user interaction and ICT developments.

- The results of the study are presented in the following sections in terms of:

- Core issues are what we recognise as most important developments in the area that will concentrate research and development efforts.

- Roadmaps are what we see as most probable elements of a future research agenda in the area.

- Potential scenarios are indicative and not necessarily representative examples of use cases that may appear in the field.
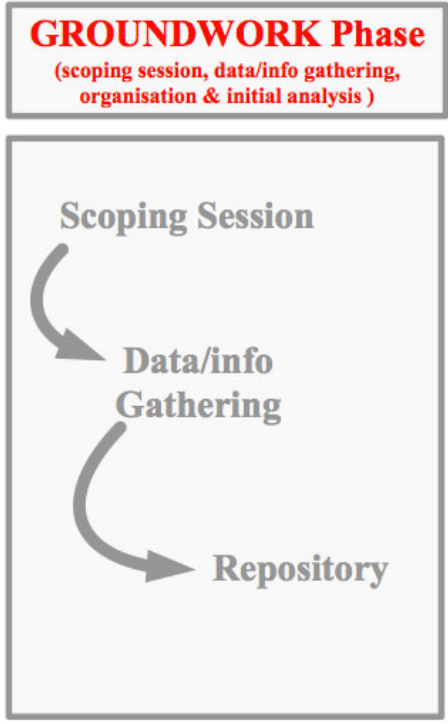
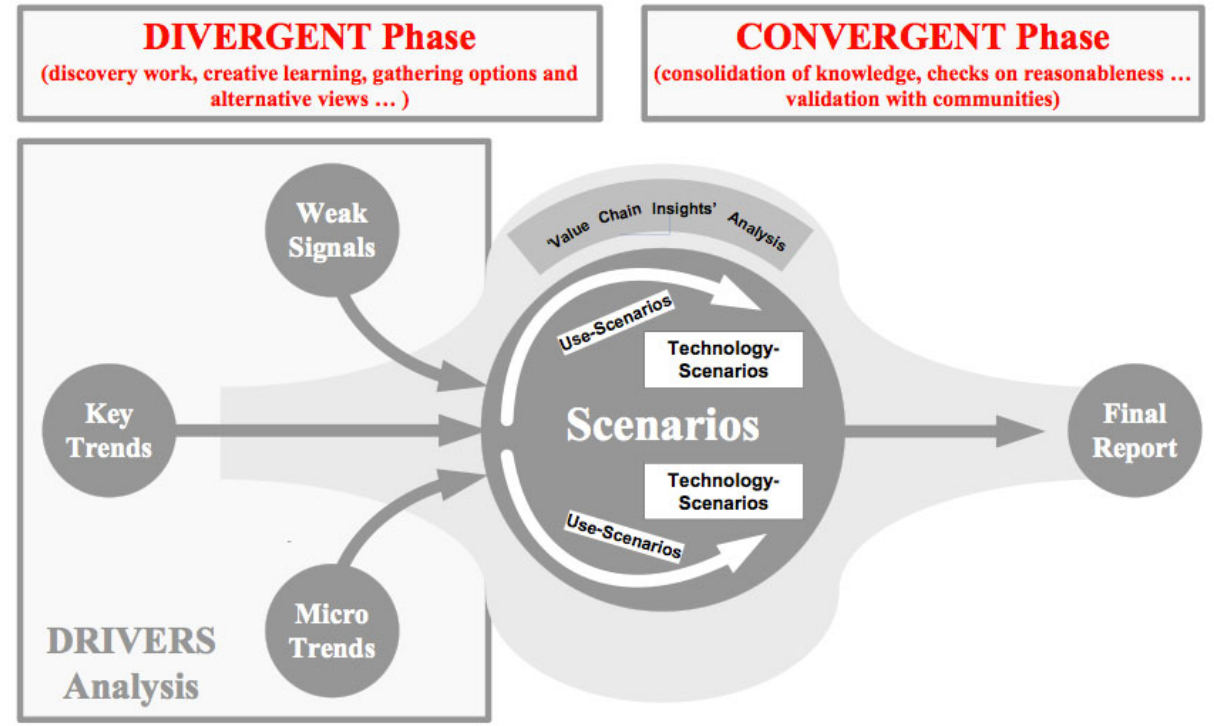

Figure 1. Accessibility2020 Study Methodology 


\section{PRIMARY AND SECONDARY SchoOl EdUCATION}

\section{A. Supporting collaborative teaching}

Both UNESCO and the European Agency set as target inclusive education. To achieve that target they both set through various documents a set of principles and techniques that could be followed. One of the techniques already tested and working in many cases during the past 2 decades is co-operative teaching. It is also referred to as collaborative teaching or co-teaching and it is when two teachers are co-operating and teach at the same time in one classroom.

Co-teaching can follow five different models [12]:

- one leads, one supports

- parallel teaching - teaching the same content to two groups, each taught by one of the co-teachers

- alternative teaching where one co-teacher teaches alternative content or using an alternative approach

- learning centres

- true team teaching that involves co-planning and shared responsibility for all aspects of instruction

There is a variety of cases of co-operative teaching such as in Norwood Elementary, in Baltimore [13], that could not all be covered in the context of this paper. There are also examples and information on how to use technology in a classroom with 2 teachers. They all prove the value of the technique, not only for children with disabilities, but also for children with learning difficulties, ADHD, autism, dyslexia etc. However, as valuable as this technique might be it is not a widespread solution. Rules and regulations of educational systems, lack of support from principals and lack of co-operation skills from teachers and lack of funding are some of the main problems preventing co-teaching to spread widely, at least for including pupils with disabilities in general classrooms.

Although there are already ideas on how to use technology in co-teaching environments, most of them are focusing on how to disseminate and use technology such as computers, electronic whiteboards, hand-held devices, etc, in classrooms. There is little research and development on software and use of technologies for teacher that co-teach. An example of software aimed to assist coteachers to improve and make their work easier is the CoTeaching Solutions Systems Package [14] which includes software for evaluating co-teaching from observers and toolbox providing teachers with resources, methods, strategies that they can follow in co-teaching. Such solutions, if provided open to educational systems, teachers, principals and other stakeholders could provide a better platform to educate teachers on how to co-operate and improve their teaching through co-teaching.

In that context, there is already a variety of Learning Management and Course Management systems for organizing, publishing and using teaching material. Such systems already allow more than one teachers to work together on producing and publishing content for a specific lesson, so they can be used as tools for co-teaching as well.

Potential scenario: Co-teaching requires both teachers to be present in the classroom and co-operate during the lesson. However, in cases of students with disabilities teachers may need to have some specific knowledge of how to handle and communicate with the student, for example if necessary using sign language. This means that teachers for students with disabilities might be needed in different places during the same day. On the other hand it means that a sign language reader could enable any teacher to work with students reliant on the use of sign language.

\section{B. Robots as assistive teachers}

In Korea a new model of co-teaching is used. They plan to have a robot in each kindergarten classroom by 2013 [15] helping in teaching English. Robots like EnKi can serve as valuable portals for telepresence [16]. In that capacity it allows Korea to hire English speakers around the world to teach in their classrooms at a fraction of the price of traditional instructors who are shipped into the country.

Potential scenario: Telepresence robots can also serve in the case of students with disabilities allowing teachers to be present in many classrooms during the same day. This way the cost of co-teaching for students with disabilities could be lowered significantly to allow coteaching to spread easier.

\section{Networking for collaborative teaching}

One of the key issues in co-teaching is the exchange of information and co-operation between wide networks of professionals in the educational sector. Being able to exchange information with other teachers, connect and find teachers for specific cases of students with disabilities and sharing good practices has already been proved

to help in improving inclusive education in general.

UNESCO in [11] conclude that one of the major areas that ICTs can help in inclusive education is supporting

international co-operation and practice exchange.

Roadmap: There is a need for more co-operation networks in teaching at international level. eTwinning [17] is one of the biggest European teacher's networks and recently the Tellnet project [18] organized a workshop to sketch out prospective scenarios about the role of teachers' networks in 2025 for teachers' professional development together with the Institute of Prospective Technology Studies in Sevilla, Spain. The document "Teacher Collaboration Networks in 2025" [19] that was produced from the workshop describes the benefits for teachers from such social networks and presents possible future solutions in that direction. However it might be useful to exploit increase participation through various policies and maybe categorize/organize better teachers for students with disabilities

\section{Personalization in Computer Supported Collaborative Learning (CSCL)}

Another interesting technique for inclusive education is collaborative learning. This is when a group of people learn something together which means that people have to depend on and help each other during the learning process. There are many different ways to implement collaborative learning and the introduction of technology in that technique has already lead to the development of a specific domain of collaborative learning called computer supported collaborative learning (CSCL).

Core issue: A crucial aspect for accessible CSCL is actually web accessibility. Since social media and net- 
works seem to heavily affect CSCL technologies, the accessibility of social networks and related applications is one of the major issues of web accessibility related with CSCL. Current social media content, blogs and Wikis etc. already pose problems for persons with disabilities so there is a need for increased awareness in the area, to help students with disabilities participate easier in CSCL activities.

Roadmap: Another aspect in such solutions is that the content is usually produced by their users. Thus, there is also a need for either increased awareness amongst users of the problems caused by content that is not accessible. Another approach in that direction could also be the development of such tools in the future to prevent users from creating and publishing inaccessible content. A category of CSCL solutions is also synchronous communication and conferencing tools. Currently, major players in the area of Learning Management Systems and Course Management Systems are offering such tools with in their platforms. Blackboard (http://www.blackboard.com/), being one of them, offers "Blackboard Collaborate" [20] in that direction, Adobe (www.adobe.com) has "Adobe Connect" [21] while traditional teleconferencing applications such as Skype (www.skype.com) and Meebo (www.meebo.com) can also be used for the same purpose.

Potential scenario: There is no indication on how accessible are these kinds of services. For example how does a person who is blind participating in a teleconference understand what is shown by the teacher who is sharing his desktop. Either the teacher has to know that there is a student who cannot see the presentation and describe it or the person is excluded from the learning process. The development of new ways of interaction with ICT such as speech recognition and gesture recognition might also help in making such tools more accessible for Persons with disabilities. In addition there is a need for personalization of the interface and the whole experience according to a user's needs. For example a student who is deaf should be able to have automatically enabled the transcripts feature of the tool in order to follow the conversation online.

\section{E. Virtual reality CSCL}

Another interesting trend in CSCL is the use of virtual worlds and gaming. Currently, there is a variety of applications on the web offering educational virtual worlds for kids that require children to complete projects and tasks, play games and throughout this process learn a variety of subjects. Web sites like JumpStart (http://www.jumpstart.com/), Club Penguin (http://www.clubpenguin.com/), Webkinz World (http://www.webkinz.com/), National Geographic Animal Jam (http://www.animaljam.com/) etc. offer various educational games, quizzes and activities in the context of a virtual world where children are learning while playing. However, there are still questions on how accessible are these kind of applications for children with disabilities.

As already presented in the consumer and lifestyle section there are already a variety of technologies for rendering virtual reality scenes such as OpenGL (http://www.opengl.org/), Direct3D (http://www.microsoft.com/download/en/details.aspx?id= 9977), Java3D (http://java3d.java.net/) and VRML (http://www.web3d.org/x3d/specifications/vrml/VRML1. 0/index.html). In addition, major companies in the ICT industry such as Sony are investing on virtual reality gear such as the new head mounted display by Sony introduced lately [22]. HMZ-11 as it is called, costs $\$ 800$ and is able to display $2 \mathrm{D}$ and $3 \mathrm{D}$ immersive scenes. The small screens in the device are equivalent of having your very own 150 inch movie screen only twelve feet away. It also a built-in virtual 5.1 surround sound headphones which can simulate a movie theatre's surround sound. Similar devices have also been presented by other manufacturers such as the WRAP1200 by Vuzix [23] and the ST1080 by SiliconMicroDisplay [24].

The devices presented earlier are mainly used for output of virtual reality scenes. However, a complete virtual reality system must also use some kind of input devices beyond the traditional keyboard and mouse. Advances in that area can be seen by Microsoft which presented Kinect [25], a camera based device which can recognize body movements, gestures and faces and provide an interaction with an Xbox device (www.xbox.com) through them. Microsoft also released an API for developers [26] in order to take advantage of Kinect's potentials by developing their own applications. From then on there's been a variety of applications coming from various developers allowing people to control and interact with their computers through movements and gestures. In August, Apple has also filed a patent [27] for a similar system allowing users to control their devices through movements showing that motion control of devices is a possible emerging trend of the future. Going some steps further in that direction some months ago, Gallotti et al. presented in a research paper a virtual reality glove (v-Glove) able to simulate touch through haptic feedback [28].

Core issue: The developments presented earlier show that the future might see virtual educational worlds being accessible in additional modalities other than the current visual one. This way virtual reality might become more accessible to persons with disabilities. Having said that it might also be useful to investigate the benefits in social and interpersonal skills of children with disabilities through virtual worlds and if they can really help them in the real world

\section{F. Augmented reality in CSCL}

Games can also be designed to promote positive interdependence. This is when students are working in groups to complete a task or a project and they have to rely on each other to succeed in completing it. Games can assign to students different roles or different parts of information and asked to collaborate in order to achieve a task. Including students with disabilities in such a process makes them feel useful in society and can increase their confidence and self-esteem. However, the nature of tasks and roles given to each member of the group and especially to children with disabilities should be so that conform with his/her abilities. Personalization of computer games in networks could lead to games taking under account a user's profile in order to assign specific tasks, roles, or pieces of information in the general game context. Such games could be very useful tools for educators in classroom settings making the learning process more engaging for everyone.

Apart from virtual reality technologies already presented to support such games there is also an emerging trend or Augmented Reality based games. In Radford University, the project called Radford Outdoor Aug- 
mented Reality designed two games based on augmented reality [29]. They gave students mobile devices with the respective software and assigning specific roles or pieces of information to each of them and asked them to complete specific tasks. However, they had to combine their information and roles to achieve the final goal. The outcomes showed AR has the potential to impact several areas of learning.

Core issue: From the accessibility perspective such augmented reality educational games can help children with disabilities in their social interactions and cooperation as long as they can access and use AR information and resources.

\section{G. Personalized education}

In all previous examples one of the key factors for inclusive education is the ability to adapt teaching methods, materials, tasks etc. according to learners' needs and profile. Either by having a co-teacher, a robot co-teacher, a traditional CSCL system, a teleconference based CSCL system or an AR based CSCL system the key factor for success is to adapt teaching methods and learning objectives according to students' needs and performance. Educators need to know how well students perform, what are their strengths and weaknesses and focus on them. This means that the learning process has to be adapted for each student individually and the traditional model of onesize-fits-all teaching and learning should be abandoned. Given however the ratio of teachers to students in schools this means that educators need tools to help them in adapting their teaching methods according to each student. They need tools to support personalized learning and assessment of their students in order to provide better personalized education services.

Today's technology with all these online courses, teaching material, educational games makes quite easy for educators to track their students' progress and find out what is needed for each of them. As Darell M. West presents it in his paper titled "Using Technology to Personalize Learning and Assess Students in Real-Time": "Imagine schools where students master vital skills and critical thinking in a personalized and collaborative manner, teachers assess pupils in real-time, and social media and digital libraries connect learners to a wide range of informational resources. Teachers take on the role of coaches, students learn at their own pace, technology tracks student progress, and schools are judged based on the outcomes they produce. Rather than be limited to six hours a day for half the year, this kind of education moves toward 24/7 engagement and learning fulltime" [30].

This kind of education described is student oriented and adapted according to each individual. In his paper West presents a variety of cases that support this kind of personalization in education and their achievements. One of the best examples is School of One in New York [31]. Students in School of One are not arranged in classrooms where they follow a specific subject according to a schedule as it happens in ordinary schools. They each get a different set of activities for each day based on their progress. This happens because School of One learns about the specific academic needs of every student and then accesses a large bank of carefully reviewed educational resources, using sophisticated technology to find the best matches among students, teachers, and resources.
In addition, School of One's learning algorithm takes upto-date data about students' performance and available materials, and creates a unique schedule for every student, every day. This way, individual students are moved ahead only after they've demonstrated mastery. Currently the program is running in three middle schools for the subject of math. However, the funding received [32] and the initial outcomes [33] encourage its expansion in more subjects and schools.

Another similar example is the High Tech High (HTH) program [34] running in 11 public charter schools in Chula Visa and San Diego, California. Students at HTH follow personal interests and develop personal portfolios of projects demonstrating their progress in various subjects. Apart from personalization, HTH has also 2 more basic design principles: adult world connection which is implemented by encouraging students to work on companies in internships and "shadow" projects and Common Intellectual Mission which doesn't separate between college preparation and technical education. The program uses a variety of teaching models assigning a staff advisor to each student who is responsible for the student and keeping contact with the family. Students with special needs receive special attention and are provided with available assistive technologies and solutions to facilitate their learning.

The iZone [35] in New York City is a program that aims to investigate innovative teaching and learning practices in schools based on digital learning. The K12 Company is also another example of personalized learning [36]. In K12 students can enrol in virtual online schools connected public school programs. The program offers personalized learning services for students who want some extra help, feel bored by the pace followed in the classroom or for any other reason they might feel that the education received in classroom doesn't satisfy their needs.

Potential scenario: In general, we can see that personalized learning is a trend in education that seems to spread a lot easier with the use of technology. This personalization, if implemented appropriately, could also help children with disabilities in their education too. They could receive special help on how to use assistive technologies, they could follow subjects on their own pace, get in groups with other students who might have similar problems in same subject and in general follow an educational program tailored to their needs and capabilities. In such an environment children with disabilities would be included gracefully in a learning environment encouraging collaboration with other students while in parallel motivating them for personal development and learning goals achievement. However, there is a need for research in the area to include even more children with disabilities in these personalized learning schemes in order to identify problems and solutions for them.

\section{H. Learning Analytics}

A keystone need for personalized learning systems and curriculum differentiation has to do with assessment of learners' progress. Assessment has to take under account specific factor for each student and adapt accordingly. Using technologies to assess students' progress can have a series of benefits [37] but most importantly it can support easier the adaptations needed for assessment for students with disabilities. Designing assessments for students with 
disabilities has to take under account various factors such as time, place, objectives etc. in order to be in equal terms with other peers [38].

Modern solutions of personalized learning presented earlier already employ a set of assessment techniques usually through online tests, quizzes and games that allow the systems to understand the learners' progress and adapt the rest of his curriculum accordingly. Using online tests, quizzes, games etc. for assessing daily progress of students can also lead to one of the first steps for achieving what is presented in "Horizon 2011" [39] report as learning analytics. Similar to Google analytics (http://www.google.com/analytics/) which can capture a web-site's users' interactions, preferences, visits, times etc. and produce graphs that visualize the use of a web site online assessments can also be used to analyse and produce similar reports for a learner, his progress, his strengths and weaknesses etc.

Since much of the assessment and teaching material is in digital form in online courses, tests, quizzes etc. there are already existing analytics tools aimed mainly for website usability testing and evaluation that could also be used in the direction of gathering learning analytics data. Solutions such as Mixpanel analytics [40] and Userfly [41] are already used in commercial sites for usability evaluation $d$ could also be used in learning analytics situation easily. An example of tool developed especially for learning analytics is Socrato [42] which can generate diagnostic and performance reports for students. Locoanalyst [43] can also provide feedback for educators on how a web-based course is used in order to improve it and ROLE [44] is a platform that also enables students to get the feedback from their learning analytics.

Potential scenario: The future might change the school into a wired school model where student complete various learning activities such as following classes, working in groups for projects and problem solving, working with teachers in small groups for specialized training and teaching in subjects that are difficult for them, consult with teachers on their assessments, projects, lessons, resources etc. All this action and interaction with various devices and interfaces will be recoded and analysed so that it is easy for teachers to point out the potential problems for each kid, adapt their teaching methods and teaching material in order to improve the learning outcomes from the whole school education/learning experience. Coupled with modern profiling systems the systems itself could suggest and support decision making for teachers giving them additional information such as what kind of disability the kid has, how they should work with him to achieve the most from its education, what kind of AT tools are best suited for him etc.

\section{Affective computing for learning analytics}

When looking at the learning analytics trend from the accessibility perspective it would probably be even more useful for educators to also include feedback of implicit students' interaction with learning systems. One of the best practices for assessing a students' progress and needs is by observing him while working on the class. This way the student not knowing that he is assessed performs naturally and shows more obvious signs of problem he might have. However, observing students in an environment such as the one described earlier might be difficult for teachers that will have to devote their time in various other tasks too. Thus, it would be helpful if the learning environment itself observes each student's behaviour. Affective computing is a technology where computers can understand emotions of people based on their implicit user input through facial expression, voice recognition, body language etc. There is already research in the area such as the Affective AutoTutor by D'Mello, Lehman and Graesser which seemed to improve the learning for low-domain knowledge learners, particularly at deeper levels of comprehension [45]. Similar research in the Institute for Neural Computing at the University of California on San Diego [46], demonstrates how facial expression can indicate various emotions of students during problem solving tasks. In another research presented in the 20th Australasian Conference on ComputerHuman Interaction [47] it is demonstrated how user agents can affect users' performance and satisfaction can change depending on how friendly the user agent is. In general there is a lot of research in the area of affective (or emotive) computing in relation to learning process and it seems as one of the promising technologies for helping students achieve better learning outcomes.

Potential scenario: Especially in the cases of children with disability where interactions with ICT might be difficult, boring or tiresome and confusing having systems that could automatically recognize such behaviour and adapt accordingly could prove very beneficial. So in the previous example of the wired school providing constant learning analytics data to teachers, emotive computing could also be used in ICTs to improve interaction and engagement in the learning process. For example, when a student who is deaf and reading a textbook chapter on Newtonian physics shows signs of boredom, the system could automatically change its method and instead of continuing with the textbook it could interrupt and use a game in order to attract his attention and connect the applications of Newtonian physics to real life.

Potential scenario: All this learning analytics data and information could also be available to the parents of a child engaging them in the learning process. The learning process will not stop in school. It will continue throughout the day with a variety of other activities which could also connect learning with real life issues and problems. For example, math could also be practiced during a visit on a shopping mall by giving the child real life situations to use them. This will engage parents in games, problem solving situation, projects, involving them actively in the learning process. This involvement would also provide teachers with additional feedback on students' behaviours and teachers could also cooperate this way with parents to adapt teaching methods accordingly. Especially in cases of children with disabilities the involvement of parents is crucial and could provide educators with valuable feedback on learning behaviour of children.

\section{J. Social media in schools}

Apart from getting education in traditional subjects such as reading, writing, mathematics, science etc. school education also provides a great deal of education in social skills. Students in schools learn basic social skills such cooperation and communication with peers, standing up for their rights, accepting differences in peoples' social background etc. Social media being an emerging trend today have also penetrated students' population. Research show that students want their schools to use social media 
for their education [48], challenging this way the boundaries between personal and professional life of educators. Social media are also affecting school education in many other ways [49] such as changing the communication between parents and children, providing more opportunities for class activities and connecting teachers with their classrooms. One of the most important aspects though, that needs attention is the effect that social media can have in the phenomenon of bullying.

Social media helped bullying spread beyond school boundaries. Bullying today doesn't stop when a student leaves school and goes home. It can continue over social media with comments, rumour spreading, uploading photos etc. It also appears that cyber-bullying is even more dangerous than bullying since according to recent studies [50] cyber-bullies and their victims have higher suicide rates than their peers. It also appears to be a phenomenon spreading quickly as technology penetrates students' lives. The same study revealed that $58 \%$ of $12-$ year-olds owned a cell phone in 2009 , up from only $18 \%$ in 2004. Research [51] also shows that cyber-bullying and bullying is prevalent among students with intellectual and developmental disability in special education settings and that is spreading silently as an epidemic [52].

However, another study [53] reveals that educators in schools are not up to speed with the developments. In a recent study, only half of teachers believed that schools are doing enough to educate students on online safety issues. Despite that, a much larger percentage of school administrators thought that education on online safety provided is enough. Another interesting finding is that a little over half of teacher felt equipped to talk to students about safety and privacy online and about cyber-bullying.

It is evident that educational systems need to get up to speed with developments in online safety and privacy issues and educators need to get up to date with such issues. Technology and social media themselves can also help in that direction. There are already applications which help in detecting cyber-bullying and inform parents and teachers respectively [54].

Core issue: Most of these applications monitor the online activity on children' computers, smart phone and tablets, with a view to alerting teachers and parents when potential harassment is taking place. Cyber-bullying is an epidemic that spreads silently and needs to be addressed both for students with and without disabilities equally. Perhaps, an additional solution to already existing programs and applications for detecting cyber-bullying could be the enhancement with users' disability profiles to help identifying easier bullying happening to children with disabilities.

\section{Higher LEVEL EDUCATION}

Higher education has many similarities with school education in techniques and practices that could be exploited in the learning process but the main difference is that students in higher education tend to be more independent from their parents/sponsors. Thus, supervision of students' progress by their parents is not as crucial as in school education. However, the role of sponsor is usually played by students themselves so there is an increased need for self-assessment and self-improvement techniques in higher education. Additionally, there is also a difference in students-to-educators ratio. Professors are not as close to students as teachers in schools leaving students with more space for initiative and creativity. This means that higher education environment fosters independency of students in their learning process. Independence in their learning process is also followed by independence in their everyday life. It is usually the age where students start to live on their own and manage real-life issues that were once handled by their parents or guardians. However, independency does not mean that collaborative learning methods or collaboration with peers is not supported. Students form their own identity while working in groups and learning to cooperate in a professional level.

From the point of accessibility in higher education a recent study published by Sachs and Schreuer [55] and reports by OECD [56] shows that enrolment of students with disabilities in higher education is lower than expected and that is followed by high first year dropout rates. It also showed that although achievements of students with disabilities are not remote to achievements of the rest of students, students with disabilities devote more time and effort and participated in fewer extracurriculum and social activities. However, the use of ICT shows improvement in the overall learning experience for students in higher education. The impact of accessible ICT through assistive technology both in education and in employment is also reported in other research $[57,58]$. One of the major barriers in inclusive education in higher education is reported to be the ignorance of faculty members and administration on issues about disabilities and how to provide solutions. In studies by Barazandeh [59] and Kraska [60] it is found that only 50\% of students with disabilities felt that faculty members understood their needs and that only $25 \%$ of faculty members were willing to change their teaching material and methods in order to accommodate their needs. The majority of students with disabilities $(82 \%)$ reported that faculty members needed to learn more about disabilities.

Looking at this evidence one can identify that technology can help in inclusive higher education but there is a definite need for raising awareness amongst the academic community on accessibility issues and how technology can help overcoming them. Inclusive education initiatives on an International level such as the International Initiative for Inclusive Education [61], on a national level such as the National Inclusive Education Initiative [62] or Inclusive Education Canada [63], together with international human rights associations such as UNESCO Enable [64] and AT ICT initiatives such as G3ICT [65], can help in that direction but what is needed is initiatives and research that takes place in higher education institutes to promote various AT.

\section{A. The case of speech recognition in universities}

An interesting example of promoting an emerging technology that could help in higher education becoming accessible for a more people is the Liberated Learning Consortium [66] which is promoting the use of speech recognition technology in education. The Liberated Learning Consortium is an international research network aiming to advanced speech recognition technologies so that they can be used in learning environments to improve accessibility. The universities and companies involved in this consortium are implementing solutions based on speech recognition technologies in learning environments. In one of their projects called Youth Initiative [67] running in Canada, students with disabilities of postsecond- 
ary school are given access to a cloud-based service allowing them to use speech recognition software to transcribe previously inaccessible letters. In another project called Synote [68] developed by the University of Southampton, students are able to search, exploit, manage and annotate lecture transcripts. This way, not only students with disabilities could access lectures and use them, but also any other student could use transcripts to have better access to lecture notes and material.

Core issue: Experience form running and past speech recognition projects in higher education shows both positive and negative signs. In most of the cases negative signs have to do with infrastructure and software problems causing it to stop running during a lecture and resulting in incomplete lecture files. Current research is also focusing on problems related to multiple speakers discussing in a classroom environment. Apart from recognizing speech from multiple speakers, the problem also involves issues of sound quality and how can you capture multiple speakers' speech in a large auditorium environment without requiring any specific microphone infrastructure installation. Interesting ideas in that direction involve even the use of mobile devices to be used as microphones from students in a large classroom/auditorium environment.

\section{B. The additional value of assistive solutions}

A very important factor that could increase the uptake of usage of speech recognition technology in classes could be the additional value that automatic transcripts and caption can add to educational material. Nowadays, almost all higher education institutes provide their student with online teaching materials such as lecture notes, presentations, sources and even lectures themselves. So, having live lecture transcripts as an additional teaching material is something that could benefit all students. In addition, combining lecture transcripts with lecture video or audio could definitely help students, apart from those with hearing impairments, by adding value to lecture video or audio. Students for example could search for a specific part of the lecture based on transcripts using technologies such as that developer in the Synote project [68], or find out lectures in other courses that deal with similar subjects.

Potential scenario: The idea of adding automatic transcripts in lectures could also evolve even more if integrated with other technologies too. Since many lecturers are already using some kind of presentation software such as PowerPoint, an additional layer of audio description could also be automatically produced during the presentation. Software for screen capturing like Camtasia Studio [69], CamStudio [70], SnagIt [71] etc. could evolve even more to capture events during the presentation such as slide change, pointer movement, animation etc. and provide additional text streams explaining actions and images on screen. These text feeds could be then used by text to speech technology to produce additional synchronized audio description feed for the presentation while this is happening.

\section{Social media as an assistive technology}

Similar feeds now can be produced and synchronized to lectures using for example Twitter. Free Power Point Twitter tools is a suite of programs by SAP [72] that can be used by lecturer as well as by any other presenter to either Tweet automatically texts during a presentation, get slides with comments, get online voting results during the presentation etc. Students can follow these tweets for additional resources and comments on a presentation. In addition there are examples that Twitter is used for engaging students in lectures [73] with live commenting from students or questions send by twitter while the presentation is taking place etc.

Potential scenario: The trend of using Twitter and other social media during lectures could provide many benefits both for student with disabilities and for students without disabilities. Students for example with speech impairment could comment or pose questions without problems. Students who are blind could follow streams for audio descriptions of slides presented in a presentation. If for example a slide show a graph representing specific statistics this could be tweeted during the lecture and read through the students mobile phone or laptop using the respective screen reader software. Other benefits include that these twitter streams could also be included as additional information layers in a recorded lectures and be used either for book marking, searching or sharing applications.

The trend of social media seems to affect heavily higher education. Actually social media can be used for many purposes even from schools [74] but in higher education uses are even more. Social media can be used for sharing information with students, communication with students, tutoring, research etc. Some examples are presented by Justin Marquis in his blog [75]. In fact, there are so many different ways to use social media that enumerating them in this report is impossible. The blog post called "Over 100 ideas for using Twitter in the Classroom" [76] proves that by refereeing to more than 100 uses only for Twitter (www.twitter.com). Let alone, Facebook (www.facebook.com), LinkedIn (www.linkedin.com), Google+ (plus.google.com), YouTube (www.youtube.com), blogs, podcasts, wikis etc. In addition, recent research is proving that the use of social media by students does not affect negatively their performance. The study shows that it is the way that students use social media that affects most their performance rather than the fact of using it. On the other hand, while nearly every student is using social media, other studies [77] show that the acceptance and usage of them in education by educators doesn't seem to show a similar uptake. The trend seems to be fighting with educators' scepticism and possibly unwillingness to change teaching tools and methods, but gains steadily more ground.

However, there are no studies on how many students with disabilities are using social media. Which ones they prefer, how they prefer accessing them (mobile, desktop), what are they using them for etc. There is also lack of data from already existing studies on how many students with disabilities were included in the studies and particular problems referred to them. Major players are showing some interest on accessibility since Facebook was recently hiring accessibility experts and according to a brief history of Facebook's communication with AFB [78] and according to AFB's blog they were open to discuss accessibility problems and committed to work on finding solutions [79]. Google who just recently launched their own social network platform stated that Google+ was built from scratch with accessibility in mind and calls for users to bring up accessibility issues in order to deal with 
them. A recent survey by WebAIM also shows trends and habits among screen reader users who also report their perception of accessibility of various social media [80]. In general the most accessible social site seems to be Twitter, possibly because of the simplicity of its interface and structure.

Core issue: Future developments in social networking tools should definitely take under account accessibility issues since there usage could become a very useful tool both for education and for other purposes too. Thus, to enable this kind of tools and make persons with disabilities more active and give them an even louder voice in the web, social networking should become more accessible through appropriate policy enforcement.

\section{The use of tablets in education}

Another interesting technology trend that begins to form in education is the use of e-readers and tablets in classroom as teaching tools. There are already many reasons why tablets would fit and could be used easily in education [81]. Tablets can spice up and make more interesting the already existing textbooks, there is already much educational software developed for tablets, they fit students lifestyle who are already using smartphones and are quite familiar with using similar interfaces and their prices are getting lower. However, there are also important barriers in scaling up the use of tablets in national level, cost being the biggest of them all and pressing for action from policy makers. In fact, South Korea [82], India [83] and Kazakhstan [84] have already announced programs that set targets for rolling out tablets in universities and schools.

From the accessibility point of view, tablets already come with a variety of assistive software such as VoiceOver [85] or Talkback [86], allowing access to persons with disabilities. In addition there are already many apps for people with disabilities [87]. Some of them are also targeted for users with cognitive disabilities or other learning difficulties [88].

Core issue: The plethora of apps for people with disabilities proves that there is potential for providing both teaching material and teaching tools (as educational apps) that do not exclude students with disabilities from the learning process. However, there is a need to make sure of the potential accessibility issues before introducing a device in education for wide use. The case of Kindle ereaders and the law that was introduced for their use in education [89] is one of the examples of how legislation and national policies should take care for accessibility before spreading widely the use of an inaccessible device.

\section{E. Tactile screens for students with disabilities}

A technology lately introduced in touch screen interfaces that could potentially increase even more accessibility of such devices is tactile touch screens. There are already a number of companies specializing in that direction with major players taking also interest in the technology. Samsung has presented Senseg (www.senseg.com), a product for tactile touch screens which as they say is quite expensive. Currently they are looking for partnerships with other device manufacturer such as Toshiba who already hopped on board to take advantage of the solution by embedding it to their products. Apple was recently granted a patent for tactile touch screens [90] and there is a lot speculation about its next product that will use this kind of technology. Microsoft has also filed a patent for tactile touch screens [91] but the technology introduced is aiming large touch screen interfaces like Microsoft's Surface [92]. Other solutions available are introduced by smaller companies like PB Interfaces [93] and Immersion [94]. However, a common issue for all the technologies and solutions for tactile interfaces introduced is their cost. As a new technology in the market it is expected to be rather expensive initially for wide adoption in education systems. The development of applications and the increase in its utility could potentially lower down the cost to reasonable levels.

Potential scenario: Obviously, tactile touch screens when introduced in tablets, smartphones or even Surfacelike devices will be able to provide a plethora of accessibility solutions for persons with disabilities [95]. The most obvious ones have to do with persons who are blind but more research could reveal potential benefits for other groups too such cognitive impaired persons. In education the introduction of tablets with tactile screens in schools could potentially solve a lot of problems existing now in teaching in large auditoriums. The most important one could be the presentation of drawings, sketches and graphs used by educators either in traditional or in interactive whiteboards. The wired university auditorium of the future could possibly include technology that will transfer the drawings form the whiteboard on a tactile touch screen of a student who is blind.

\section{F. Opening higher education and distance learning}

Another very interesting innovation in education that is emerging especially in higher education is what is called democratization of education. It started some years ago with the introduction of Open University in UK (www.open.ac.uk). The Open University contrary to what was the norm up to date is accepting students without any specific qualification criteria opening up access to higher education. Students can choose from a variety of courses offered and study from their own home though distance learning technologies. What is important from the accessibility point of view is that the Open University has “...over 12,000 students with a disability, health condition, mental health difficulty or specific learning difficulty (such as dyslexia) study at the OU" according to their site [96]. Other interesting initiatives for opening access to higher education learning were recently announced and deployed by MIT and University of Stanford. The University of Stanford has already opened access to lectures of three courses [97] and plans to now open access to even more in the following semester. MIT has recently announced a new open source learning initiative called MITx [98]. The examples indicate a trend for opening access to higher education learning through distance learning applications and technologies. This could prove to be of significant importance for people with disabilities that are often discouraged by the barriers confronted with access to the university itself. It could be access to the campus, within the campus reaching the classrooms, following lectures live, participating in extra-curriculum activities etc. All this fuss and problems that might seem trivial can discourage a person with disability when he has to deal with them every day. So, opening up access to education could also give many people with disabilities a second chance to higher education. 
Core issue: A reason why Universities start investing in distance learning courses is also the cost. Distance learning doesn't need classrooms or labs and consequently is not limited by such factors. The potential audience for an online lecture could be hundreds of thousands of people all over the world whereas the same lecture could be followed only by a limited number of students in a classroom or auditorium environment. However, there are cases in higher education where presence in a specific place could be off importance and could not be substituted by distance learning techniques such as attending a lab session.

As already explained earlier, access to universities, even if there is increasing awareness and provision, still poses problems in many cases. A technology that could help in that direction could be that of telepresence robots. Telepresence robots presented also in previous sections such as those provided by Anybots [99] and Vgo Communications [100] could potentially be used within a university environment so that students with disabilities can attend lectures, lab sessions, workshops etc. by using a telepresence robot.

\section{G. Producing and repurposing content for open distance learning}

As distance learning and open learning technologies get more traction there will be a need for educators to produce more teaching material and a lot easier. Capturing a lecture with software like Camtasia Studio [69], CamStudio [70] or SnagIt [71], could be already quite easy. However, content produced with such software could be very inaccessible. On the other hand a lecture presentation file on its own might quite accessible but without being able to access the actual lecture loses some of the information. Being able to access the lecture video and the presentation file at the same time could be very helpful for students with visual impairments. In parallel, a text stream of tweets about the lecture, comments and questions could also add more value and interactivity to the lecture. All this and many more layers of information that could accompany a lecture video such as live transcripts or captions, additional resources for specific issues discussed during the lecture etc. could make easier the learning experience for a student with disabilities and enhance even more the experience for the rest of the students. Thus, there is a need for media and media production and consumption tools that could easily tailor all this information together, publish it and use it as needed.

Potential scenario: There are already media formats that could tie media such as video or audio with additional metadata. Having all this additional information as metadata layers could enrich significantly the learning experience. Imagine for example the auditorium of the future capturing the video feed of the lecture, synchronizing it with events in the presentation such as slide or text and image transitions, tying also events in social media such as posts on the lecture's Facebook page or on Twitter, following and capturing audience responses to questions, level of attention and mood during the lecture from various students interactions, producing and adding audio transcripts and finally producing an overall media content file that includes all the above meta information. The content is also automatically broadcasted though internet, so that it can be followed live by students at their home. Additionally the educator after some editing and correc- tions on the content also uploads the lecture content on the university's media server. Students that either have attended the lecture or not could then have access from a special media player that could allow them to configure which layers of content to see and which not adapting this way the presentation to their needs.

Another issue that follows also the problems described earlier is technologies that can help in repurposing of existing content. For example, how can a textbook written in a word processor are easily transferred to material for a web page? How accessible this web page will be? How easily the textbook can be used from an e-Reader, a tablet or a mobile phone? Although technologies and standards in the filed have evolved there are still important issues in repurposing of content even for the already existing technologies. New technologies will amplify these problems if standards common practices are not followed.

\section{H. Personalizing assessment}

Another need not examined so far in higher education is the one for assessment of learning progress. In the previous section of school education the technology of learning analytics was presented and examined in relation to students with disabilities. The main difference between school and higher education assessment is that the first one is mainly targeted to educators who follow students' progress and adapt their teaching methods and tools, whereas in higher education it should be intended mainly for use by students themselves. Students seeing learning analytics reports should be able to see their progress compared to other students following the same subject and adjust accordingly their own learning tools and methods. It could be that the tools themselves provide them with decision support mechanisms and provide them with possible solutions in adjusting their learning experience.

Potential scenario: In the case of students with disabilities however, learning analytics should also take under account disability in the learning process. As explained in [38], assessment of students with disabilities might need adaptations in time, nature, objectives on order to be on equal basis with other students. Learning analytics tools should know and take under account those factors in order to provide information that is in comparison with the rest of the students. For example, knowing that a student who is blind take more time to read through a page of a textbook and this time might also increase in case there are math involved, the tool should adapt the time needed for the student who is blind in similar scale with the rest of the students in order to show him that he is following at the same pace. In that direction there is a need for more research to understand even better how these adaptations work.

\section{LIFELONG LEARNING FOR LIVING AND WORKING}

Some might say that learning is a process that ends with the graduation from a university. These ideas now belong to the past. People are required throughout their life to constantly learn new skills, new tools, new methods etc. Current work environments and the rapid changes in technology and science require persons in almost all professions to stay up to date with trends, news and developments in their area of interest. Thus, there is a need for constant learning in all stages of life of a person. Vocational education and training though doesn't neces- 
sary follow traditional educational schemes of educators teaching in a classroom a group of learners. In many cases this training is happening in a self-training mode. People follow self-training courses or tutorials and learn new skills. As all other people, persons with disabilities also need this kind of vocational training and education to develop professionally as their colleagues. So, it is essential to ensure that this kind of training and education is accessible to persons with disabilities too. However this section will not analyse further such issues because they are very well analysed at the section on employment and employability.

Disability however, has another additional connection with education and training. People who are disabled from birth or become disabled in young ages as already explained should be included in general educational systems. People with disabilities whether they are born with them or whether they become disabled later in life need to learn additional skills for their everyday living. They mainly have to learn how to adapt old habits and skills in ways that fit their current status. For example, a person who is left blind after an accident in work environment will need to learn how to cook, take care of his personal hygiene, walk and orientate within the home or city environment, use a white cane, read Braille etc. This indicates that a disability itself is also a source for new educational and training needs.

Similarly, there is a gradually increasing need of training for an ageing population with decreasing capabilities. Ageing people, with decreasing capabilities in hearing, seeing, remembering, etc. need a gradual training to adapt their lifestyles to their new capabilities. These training needs in some cases resemble the needs of a person that becomes disabled due to an accident or illness.

Today there are an increasing number of AT solutions for all kinds of disabilities and possible problems. National policies on how to help people with disabilities getting appropriate training vary from country to country within the EU. ViPi (http://www.vipi-project.eu/) an EU project recently funded by the EU LifeLong Learning Programme stresses out in its launch announcement that "Recent studies conducted by various projects such as ACCESSIBLE and AEGIS have highlighted that people with disabilities (persons with disabilities) can benefit enormously from digital competences which are core life and employability skills (see Lisbon Objectives). However, same and other studies revealed also that the main barrier is the lack of specific training support or material" [101]. Projects like ViPi which aims to provide people with disabilities a platform with training material on ICT usage and trainers to upload training courses, games and material can help in connecting people with disabilities with trainers.

However, the aim of the project is to provide a platform for training Persons with disabilities on using ICT. As already highlighted there is also a need for training on everyday issues and tasks and the use of various other AT devices. Although, there are a number of other projects fostering research and development in the area of assistive ICT such the ETNA [102], ATIS4ALL [103], AAATE [104], FAST [105], etc., there are limited resources on centres and organizations that provide training to people with disabilities, advice on assistive technologies available etc. such as the Danish Centre of Assistive Technology [106] or the Queen Elizabeth's Foundation [107].
People with disabilities searching for information on special education and training and advice centres are often overwhelmed with fragmented information from various sources which might disorientate and discourage them from looking further into it.

Core issue: In the area of life long learning there is a need for better organization and a central information point on various sources, organizations, centres and the services different learning solutions provide. Future policies should look further into providing centralized information of resources available for training for living. This gathering of information will also bring to front differences in resources available among EU countries and policies followed and will also help EU to form a better overall policy on training for living resources for people with disabilities.

\section{A. Smart homes training Persons with disabilities}

People learning to live with a disability are usually beginning the adaptation process within the home environment. Advances in the area of smart homes reveal that there might be potential for providing such training services through smart home environments. Smart home projects such as the I2Home [108] which presented an EU smart-home concept show that disabled users could benefit in everyday activities, health and social care services with the assistance of smart homes [109]. Although, there is no indication up to now on how such smart environments can also be used for training of people acquiring a disability to be trained in their everyday-life activities, one can see the potentials. When the smarthome will know that the person in the home is someone who recently became deaf from an accident it could adjust appropriately various functions to train the person on sign language. For example it could provide small video clips of an avatar showing him sing language expressions related to his current activity. When cooking, it could show him in a display on the fridge how the expression "I am cooking" is in sign language.

However as identified by Guy Dewsbury, smart homes have to deal with a variety of issues in order to become widely adopted [110]. The four major categories that can group these issues are:

- Fitness for Purpose

- Trustworthiness

- Usability

- Adaptability

Core issue: In an interview he also says that "What is evident is that there are a small number of people in the UK who are working closely in this area and developing new solutions and changing the way we can think about how technology can support people. If their work gets into the public domain and is publicized correctly then the future is very bright. I also should say that manufacturers of smart home technology should also come on board and begin to consider lowering their prices as this would make this option more viable in the long term. I personally see the future as very good indeed. I can see a future where smart homes are standard and not unique."'[111]

\section{B. Gaming for training Persons with disabilities}

An interesting trend emerging in training both for vocational training and for general training for a variety of reasons has to do with gaming. Serious games is a cate- 
gory of games that aims to educate and train people through games that are more engaging and fun as a learning process than reading books and other traditional ways of learning. Games like IBM CityOne [112], FloodSim [113], PeaceMaker [114], A force more powerful [115], etc. teach people issues in civil engineering, peaceful negotiations, nonviolent methods of fighting for rights etc. Serious games are also used for vocational training such as Microsoft's Flight Simulator [116] which is used for training on civil aviation rules.

The trend has also started getting exploited for people with disabilities too. Projects like GOAL NET [117], GOET [118] and RECALL - KA3 [119] project have already started investigating the potentials of serious games in training people with disabilities. The games produced from these programs are used to educate people with sensory or cognitive disabilities in a variety of skills either for employment or for their everyday life. The CapAbility Games Research Group in Rensselaer Polytechnic Institute [120] is a research group aiming to provide persons with disabilities with games that train them in basic life skills such as personal care, job readiness, money management, household management and other areas.

Core issue: A crucial aspect pointed out by David Brown and Penny Standen in their interview for Platform Online [121] is that in serious games the players can repeat an action over and over again and learn from the results of each action. For example, it can describe and simulate the consequences of crossing a street without paying attention to the traffic lights without actually getting the person in danger.

Serious games have already started evolving by using advances in Virtual and Augmented Reality technologies. Virtual reality and immersive environments allow serious game developers to reproduce whole environments and use them for training people with disabilities. There is already evidence that games using immersive environments can be more effective and engaging for learners [122], but there is also quite a lot ground to be covered in research and development. Some of the problems referred to the aforementioned source are also the cost of equipment and potential health and safety issues from the usage of equipment such as head mounted displays. The paper was presented in 2006 and now costs are getting lower in VR devices however there is still a lot of research needed on how VR systems can become accessible to persons with disabilities.

The rise of mobile devices and mobile computing though brought to light another interesting technology for serious games. Augmented Reality (AR) can be easily used from a person's mobile device and one of the major application it is used is gaming. This makes possible the development of serious games for training persons with disabilities while interacting with their everyday real life environments.

Core issue: For example, a treasure-hunting game for blind persons in their city could train them to orientate and navigate in city environments. However, this is an area that now starts getting exploited. Comparing VR and AR we can see that future AR solutions for serious games could emerge easier and have a greater impact since their ease of access and use is significantly better than VR ones. However, VR has the advantage of simulating circumstances and environments that are probably dangerous for training in reality.

A lot of serious games are developed to educate people in a variety of social skills such as conflict management and cultural differences. This means that serious games could be used not only for training persons with disabilities. They could also be user to educate and train societies on problems of persons with disabilities. This could lead to societies of the future with better understanding of people with disabilities needs and consequently more sympathetic for them. For example, a VR game simulating your moving around the city using a wheelchair could get a lot of people to understand the problems they are causing to motor impaired person when parking in their parking spaces or in front of ramps on pavements. An additional incentive to that kind of games can be given if combined with social networking media.

Potential scenario: A game that gets you various situations where you need to help and interact with a person with disability and giving points depending on your reactions could give you an incentive to prove to your friends how good you are in such situations and could help you find out possible misconceptions of what an appropriate behaviour to a Persons with disabilities is. It could also help people recognize easier disabilities (especially in cases of cognitive ones) by learning more about them during the game.

\section{Mobile device as a trainer}

Similarly to persons acquiring a disability due to an accident or illness there is also a large part of ageing population who have gradually decreasing capabilities reaching slowly towards disability levels. One of the biggest fields of research and market in that direction has to do with brain training apps and cognitive therapy. Companies like Lumocity [123] provide a series of mobile apps that can be used for training peoples' brains through variety of games. Mobile app markets are now flooded by games for brain training such as Sudoku and other kinds of puzzles, memory games, word games etc.. Although there is a debate whether such apps and brain games in general improve cognition [124], it is evident that people practicing in a specific skill through games get better on it. Other issues with mobile games pointed out in a study on the University of Belfast [125] are mainly usability and poor communication issues as de-motivation factor for continuing playing such games.

Core issue: The brain training apps trend and cognitive therapy through brain games is an area still to be exploited and it is further analysed in the health and social care section. However, it is crucial to point out that mobile brain games for seniors is an area that faces a bigger challenge, namely how to motivate elderly to use smartphones in the first place? Some argue that future elderly generation will be used in smartphones usage and will want to continue using them but there is still no strong evidence of this happening. So some of the questions rising form mobile brain games for elderly are:

\section{TEACHING AND LEARNING INNOVATION ISSUES}

\section{A. Issues of action research}

The main method of research employed by people involved in fields such as education and management is Action Research [126], also often referred to 
as Participatory Action Research [127]. For those who practice either of them, research in the form of experimentation and reflection is embedded into their everyday work. As they work they constantly experiment with new tools, textbooks, ways of teaching or ways of working in a learning environment. In principle, every act of work can be seen as an experiment and provide food for reflection on the result. Working with colleagues or on one's own is possible to draw conclusions, design new experiments and steadily improve outcomes over time.

This is very different from the way research is done in chemistry or physics. One hydrogen atom is just like any other and a chemist reasonably expects the properties of one to be identical with the properties of another. The same does not apply in areas such as teaching, medicine or management. No two teachers or students are alike. No two classes are ever the same. The curriculum constantly evolves. An experiment in learning modifies both the teacher and the student so that the 'same' experiment can never even be performed on the same teacher-student pair. When an experiment is repeated, the teacher becomes more experienced, the student will have learned something new, and so it becomes impossible to carry out the exact same experiment with the exact same set of conditions.

The same argument holds in the case of e-access research and development. Technologies intended to help someone with a disability face the challenge that disability is a vague and expanding concept. Every disabled person is first of all a person with their own unique set of qualities, all of which come into play when they use an assistive technology. Some disabled people are able to run faster than most non-disabled people. Few non-disabled people will ever compose music as innovative and enduring as Beethoven did despite being deaf.

Core issue: Despite this difficulty real progress is possible. A large body of practice has developed over the years to support research and progress in areas such as teaching and learning. It may be desirable in future ICT programmes to give explicit weight to the research methods of the social sciences such as Action Learning, in the application of ICT to domains such as e-access ICT research for teaching, training and learning.

Roadmap: The techniques of Action Learning, Activity Research and Participatory Action Research are routinely used in the development of domains such as technologies for teaching and learning and many of the research presented in this section is based on these principles. However, the pace of change is furious. There may be a need to ensure that people with disabilities are systematically included in this kind of research effort so that the requirements of people with special needs are fully considered in future research programs.

\section{B. The Hawthorne effect}

Another issue that needs attention in research related with education, teaching and learning is the Hawthorne effect. Lots of business books deal with this, as well as magazines such as the Harvard Business Review [128], but it is not a difficult concept and Wikipedia explains it very well [129]. It is a kind of placebo effect, whereby the productivity of a group under study improves merely because of the attention being paid to it by management. A manager who does not know about the Hawthorne effect will easily mistake what is in reality only a short term productivity boost, for a permanent productivity boost, brought about by the clever nature of the manager's intervention.

The phenomenon was discovered by Henry Landsberger in Chicago in the 1950s when he analysed the results of work productivity experiments carried out at Hawthorne works in 1924-1932. There is still some discussion among experts as to what is the real cause of the Hawthorne effect, though the phenomenon itself seems to be real and has been borne out by many subsequent experiments.

Core issue: In the case of accessibility research especially related with education and learning this could also be the case in some situations. People with disabilities might seem to benefit for the period that the study runs. However, looking at long term results of a research might prove that the benefits and boost in learning achievements was just temporary due to the Hawthorne effect. It should be pointed out that positive outcomes from research in education should provide evidence that the learning experience itself was improved not just by boosting the results in short term exams but by providing lasting outcomes. A person who improves his learning experience is expected to boost his performance in long term and show evidence of lasting effects. Thus, it is essential that research programs related with people with disabilities in education take under account this factor and examine carefully their results.

\section{Scaling up}

Finally when it comes to education research and innovation one of the biggest problems is scaling up.

During the research for this section we came across numerous cases of education innovations and research that was applied locally on a number of schools, universities and educational institutes but stayed there. It never succeeded in scaling up and reforming education systems, practices, methods etc. One of the reasons might be explained by the Hawthorne effect presented earlier but this is not always the case.

A variety of reasons are presented in [130]. One of the most important issues presented is funding. Research and innovation is easy to get funding when it is about a small number of cases. However, when scaling a lot more funding should be found and national policies usually lack the ability and willingness to support it. Other issues presented are increased experts interest in research which fades out when scaling, increased enthusiasm which also fades out when confronting problems in scaling and need for changes in accommodation which may prove difficult to meet when scaling. However in a response article in [131] it is pointed out that education innovation can thrive when it:

- Produces strong evidence of effectiveness

- Can be funded by stable sources

- Is supported by strong organizations and committed networks of dedicated educators

- Communicates a very strong and clear vision of the future and the path to get there

- Provides intensive professional development for educators in early years of implementation while in parallel ensures the maintenance of quality for the future. 
Core issue: Given those factors we can understand the problems that some of the scenarios presented in this section might have in scaling up. Despite that, this report intends to provide a variety of scenarios for the future of education for persons with disabilities and become the starting point of discussions which will lead to specific recommendations. So, it's worth investigating as many options as possible.

\section{CONCLUSIONS}

The results of the eAccessibility 2020 study highlight some of the most prominent research fields which can affect the quality of special education in the next 10 years. First of all, at the level of access, assistive technologies (such as speech recognition and tactile screens) are still considered very important, and they should be available and compatible with new and emerging devices (tables and smart phones) and technologies (virtual reality, augmented reality). Moreover, collaboration, especially through social media, is considered to be the key for the improvement of teaching and learning for special needs. As for the main technologies which are considered as most important for special education, they include affective computing, gaming, learning analytics, robotics and smart home environments.

In all expert responses it was highlighted that the key to high-quality special education is personalisation in content and services. Student have quite different profiles, therefore any single, one-size-fits-all solution cannot address their different needs, abilities and preferences. We need to develop systems which can adapt to each individual learner and the learning context in general. The rapid evolution and adoption of mobile and ubiquitous technologies can offer an additional motivation for research in this direction, since in such environments all learners can be "disabled" for specific time periods due to their context of use (and not due to "traditional" disability): for example, the learner cannot use the screen for some time not because she/he is blind, but because her/his vision is diverted to another task. Such solutions can result in the re-definition of the term disability (and accessibility), as reflected and envisioned in [132]: "The term disability has been re-defined as a mismatch between the needs of the learner and the education offered. It is therefore not a personal trait but an artifact of the relationship between the learner and the learning environment or education delivery. Accessibility, given this re-definition, is the ability of the learning environment to adjust to the needs of all learners. Accessibility is determined by the flexibility of the education environment (with respect to presentation, control methods, access modality, and learner supports) and the availability of adequate alternative-butequivalent content and activities. The needs and preferences of a user may arise from the context or environment the user is in, the tools available (e.g., mobile devices, assistive technologies such as Braille devices, voice recognition systems, or alternative keyboards, etc.), their background, or a disability in the traditional sense. Accessible systems adjust the user interface of the learning environment, locate needed resources and adjust the properties of the resources to match the needs and preferences of the user."

\section{REFERENCES}

[1] World Education Forum, Dakar, Senegal, 26 - 28 April 2000,http://www.unesco.org/education/wef/en-conf/index.shtm

[2] UNESCO Education for All Goals, http://www.unesco.org/new/en/education/themes/leading-theinternational-agenda/education-for-all/efa-goals/

[3] UNESCO, Understanding and Responding to Children's Needs in Inclusive Classrooms: A Guide for Teachers, 2001, http://unesdoc.unesco.org/images/0012/001243/124394E.pdf

[4] UNESCO, Changing Teaching Practices using curriculum differentiation to respond to students' diversity, 2004,http://unesdoc.unesco.org/images/0013/001365/136583e.pdf

[5] Cor J.W. Meijer,Special Needs Education in Europe: Inclusive Policies and Practices, ZeitschriftfürInklusion, Nr. 2 (2010), http://www.inklusiononline.net/index.php/inklusion/article/viewArticle/56/60

[6] European Agency for Development in Special Needs Education, Inclusive Education and Classroom Practice: Summary Report, March 2003, http://www.europeanagency.org/publications/ereports/inclusive-education-andclassroom-practices/iecp-en.pdf

[7] European Agency for Development in Special Needs Education, Key Principles for Promoting Quality in Inclusive Education: Recommendations for Policy Makers, 2009, http://www.europeanagency.org/publications/ereports/key-principles-for-promotingquality-in-inclusive-education/key-principles-EN.pdf

[8] European Agency for Development in Special Needs Education, Inclusive Education and Classroom Practice in Secondary Education: Summary Report, 2005, http://www.europeanagency.org/publications/ereports/inclusive-education-andclassroom-practice-in-secondaryeducation/iecp_secondary_en.pdf

[9] European Agency for Development in Special Needs Education, Assessment in Inclusive Settings: Key Issues for Policy and Practice, 2007, http://www.european-

agency.org/publications/ereports/assessment-in-inclusive-settingskey-issues-for-policy-and-practice/Assessment-EN.pdf

[10] European Agency for Development in Special Needs Education, Special Needs Education Country Data 2010, Revised version: December 2011, http://www.europeanagency.org/publications/ereports/special-needs-education-countrydata-2010/SNE-Country-Data-2010.pdf

[11] UNESCO Institute for Information Technologies in Education, ICTs In Education for People with Disabilities: Review of innovative practice, 2011, http://www.europeanagency.org/publications/ereports/ICTs-in-Education-for-PeopleWith-Disabilities/ICTs-in-Education-for-people-withdisabilities.pdf

[12] C. Y. Mason, Co-Teaching with Technology: The Power of “3”,http://www.edimprovement.org/wpcontent/uploads/2010/09/Co-Teaching-with-Technology.pdf

[13] L. Heitin, Pairing up: A Maryland initiative seeks to scale up coteaching as a way to support students of all needs, Vol. 05, Issue 01, Page 26, October 2011, http://www.edweek.org/tsb/articles/2011/10/13/01 coteach.h05.ht $\underline{\mathrm{ml}}$

[14] Co-Teaching Solutions Systems http://www.coteachsolutions.com/

[15] A. Saenz, Another Robot Teacher Enters Korean Classrooms, February 2011, http://singularityhub.com/2011/02/26/anotherrobot-enters-korean-classrooms-as-automated-teaching-advances/

[16] A. Saenz, A Robot in Every Korean Kindergarten by 2013?, November 2010,http://singularityhub.com/2010/11/02/a-robot-inevery-korean-kindergarten-by-2013/

[17] http://www.etwinning.net/

[18] http://www.tellnet.eun.org/web/tellnet;jsessionid=0EAF6638D4D 5B887A228FE6E263D3716

[19] M. Bacigalupo, R. Cachia, Teacher Collaboration Networks in 2025: What is the role of teacher networks for professional development in Europe?, Notes from the Workshops held on the 6th and 7 th June 2011 at the Institute for Prospective Technological Studies of the European Commission Joint Research Centrehttp://ftp.jrc.es/EURdoc/JRC67530 TN.pdf 
[20] http://www.blackboard.com\Platforms\Collaborate\Products\Black board-Collaboratelwhats-new.aspx

[21] http://www.adobe.com/products/adobeconnect.html

[22] http://www.soundandvisionmag.com/blog/2011/11/16/sony-s-3dheadset-virtual-reality-goes-mainstream

[23] http://www.vuzix.com/consumer/products wrap_1200.html

[24] http://www.siliconmicrodisplay.com/st1080-features.html

[25] http://www.xbox.com/en-US/kinect

[26] http://www.microsoft.com/en-us/kinectforwindows/

[27] http://mashable.com/2011/12/09/apple-itv-gestures/

[28] P. Gallotti, A. Raposo,L. Soares, v-Glove: A 3D Virtual Touch Interface, 2011 XIII Symposium on Virtual Reality (SVR), Uberlândia - Minas Gerais, Brazil, 23-26 May 2011 http://dx.doi.org/10.1109/SVR.2011.21

[29] http://gameslab.radford.edu/ROAR/games.html

[30] D. M. West, Using Technology to Personalize Learning and Assess Students in Real-Time, Brookings Institute, October 2011, http://www.brookings.edu/ /media/Files/rc/papers/2011/1006 per sonalize_learning_west $/ 1006$ personalize_learning_west.pdf

[31] http://schoolofone.org/concept.html

[32] http://schoolofone.org/partners funding.html

[33] http://schoolofone.org/resources/sol quickfacts.pdf

[34] http://www.hightechhigh.org/

[35] http://schools.nyc.gov/community/innovation/izone/default.htm

[36] http://www.k12.com/

[37] http://teaching.unsw.edu.au/assessment-technologies

[38] http://www.teachability.strath.ac.uk/chapter_8/reflectingonpractic e8c.html

[39] Johnson, L., Smith, R., Willis, H., Levine, A., and Haywood, K., (2011). The 2011 Horizon Report. Austin, Texas: The New Media Consortium, http://wp.nmc.org/horizon2011/sections/learninganalytics/

[40] https://mixpanel.com/

[41] http://userfly.com/

[42] http://www.socrato.com/

[43] http://jelenajovanovic.net/LOCO-Analyst/

[44] http://www.role-showcase.eu/home

[45] S. K. D’Mello, B. Lehman, A. Graesser, A Motivationally Supportive Affect-Sensitive AutoTutor, in New Perspectives on Affect and Learning Technologies, Explorations in the Learning Sciences, Instructional Systems and Performance Technologies, Volume 3, 2011, pp 113-126

[46] G.C. Littlewort, M.S. Bartlett, L.P. Salamanca, J. Reilly, Automated measurement of children's facial expressions during problem solving tasks, 2011 IEEE International Conference on Automatic Face \& Gesture Recognition and Workshops (FG 2011), 2125 March 2011

[47] N. Perera, G. Kennedy, J. Pearce, Are you bored?: Maybe an interface agent can help!, OZCHI '08 Proceedings of the 20th Australasian Conference on Computer-Human Interaction: Designing for Habitus and Habitat, Pages 49-56

[48] http://blogs.kqed.org/mindshift/feature/children-and-social-media/

[49] http://mindshift.kqed.org/2010/11/6-ways-social-media-ischanging-education/

[50] http://www.ama-assn.org/amednews/2010/11/15/prl21115.htm

[51] Robert Didden, Ron H. J. Scholte, Hubert Korzilius, Jan M. H. de Moor, Anne Vermeulen, Mark O'Reilly, Russell Lang, and Giulio E. Lancioni, Cyberbullying among students with intellectual and developmental disability in special education settings, Developmental Neurorehabilitation, 2009, Vol. 12, No. 3 : Pages 146-151 http://informahealthcare.com/doi/abs/10.1080/1751842090297135 6?journalCode=pdr\&, http://dx.doi.org/10.1080/1751842090297 $\underline{1356}$

[52] http://www.disabled-world.com/disability/education/special/bully ing-special-needs.php

[53] A. Watters, How Well Are Schools Teaching Cyber Safety and Ethics?, May 19, 2011 http://blogs.kqed.org/mindshift/2011/05/how-well-are-schoolsteaching-cyber-safety-and-ethics/
[54] S. Bernard, 5 Apps That Could Help to Stop Cyberbullying, December 10, 2010 http://blogs.kqed.org/mindshift/2010/12/5apps-that-could-help-to-stop-cyberbullying/

[55] D. Sachs, N. Schreuer, Inclusion of Students with Disabilities in Higher Education: Performance and participation in student's experiences, Disability Studies Quarterly, Vol 31, No 2 (2011)

[56] OECD Publishing, Education and Training Policy: Inclusion of Students with Disabilities in Tertiary Education and Employment, May 2011

[57] P. W. Dowrick, J. Anderson, K. Heyer, J. Acosta, Postsecondary education across the USA: Experiences of adults with disabilities, Journal of Vocational Rehabilitation, Volume 22, Number 1/2005, pp. $41-47$

[58] N. Schreuer, A. Rimmerman and D. Sachs, Adjustment to severe disability: constructing and examining a cognitive and occupational performance model, International Journal of Rehabilitation Research, 2006, 29

[59] G. Barazandeh, Attitudes Toward Disabilities and Reasonable Accommodations at the University, The UCI Undergraduate Research Journal, 2005

[60] M. Kraska, Postsecondary Students with Disabilities and Perceptions of Faculty Members, Volume 25, Number 2, The Journal for Vocational Special Needs Education, 2003

[61] http://www.equityallianceatasu.org/ii

[62] http://www.iod.unh.edu/Projects/archived/niei/program_descriptio $\underline{\text { n.aspx }}$

[63] http://www.inclusiveeducation.ca/english/index.asp

[64] http://www.un.org/disabilities/

[65] http://g3ict.com/

[66] http://liberatedlearning.com/

[67] http://transcribeyourclass.ca/index.html

[68] http://synote.org/synote/

[69] http://www.techsmith.com/camtasia.html

[70] http://camstudio.org/

[71] http://www.techsmith.com/snagit.html

[72] http://timoelliott.com/blog/powerpoint-twitter-tools

[73] G. Ferenstein, How Twitter in the Classroom is Boosting Student Engagement, http://mashable.com/2010/03/01/twitter-classroom/

[74] D.Hartstein, How Schools Can Use Facebook to Build an Online Community,http://mashable.com/2011/04/26/facebook-forschools/

[75] J. Marquis, Using Social Media in the Higher Education Classroom, September 2011

http://www.onlineuniversities.com/blog/2011/09/using-socialmedia-in-the-higher-education-classroom/

[76] K. Walsh, 100 Ways to Teach with Twitter, February 2010http://www.emergingedtech.com/2010/02/100-ways-toteach-with-twitter/

[77] H. Tinti-Kane, J. Seaman, J. Levy, Pearson Social Media Survey 2010, April 2010

http://www.slideshare.net/PearsonLearningSolutions/pearsonsocialmediasurvey 2010

[78] http://www.simplyraydeen.com/faq/48-web-site-accessibility/71facebook-works-with-the-blind-on-accessibility

[79] http://www.bitvtest.eu/articles/article/lesen/fb-accessibility.html

[80] http://webaim.org/projects/screenreadersurvey2/

[81] V. Madan, 6 Reasons Tablets Are Ready for the Classroom, May $2011 \mathrm{http} / / /$ mashable.com/2011/05/16/tablets-education/

[82] P. Murray, South Korea Says Good-Bye To Print Textbooks, Plans To Digitize Entire Curriculum By 2015, October 2011 http://singularityhub.com/2011/10/25/south-korea-says-goodbye-to-print-textbooks-plans-to-digitize-entire-curriculum-by2015-video/

[83] L. Y. Qing, India to debut $\$ 45$ Android tablet for education, October 2011 http://www.zdnet.com/india-to-debut-45-androidtablet-for-education-2062302369/

[84] D. Drinkwater, Kazakhstan to bring tablets to all school children by 2020, November 2011

http://tabtimes.com/news/education/2011/11/14/kazakhstan-bringtablets-all-school-children-2020 
[85] http://www.apple.com/accessibility/ipad/vision.html

[86] http://www.androidzoom.com/android_applications/tools/talkback eq.html

[87] http://www.disabled-world.com/assistivedevices/apps/

[88] http://appsineducation.blogspot.gr/2011/12/monster-list-of-appsfor-people-with.html

[89] D. Schaffhauser, Department of Ed Lays Down Law on Kindle EReader Usage, June 2010

http://campustechnology.com/articles/2010/06/29/department-ofed-lays-down-law-on-kindle-e-reader-usage.aspx

[90] G. Wong, Apple granted patent for "bumpy" tactile touchscreens, April 2011 http://www.ubergizmo.com/2011/04/apple-patenttactile-touchscreens/

[91] C. Dillow, Microsoft Building Shape-Shifting Touchscreen For True Tactile Touch Tech, December 2010 http://www.popsci.com/technology/article/2010-12/patent-filingreveals-microsofts-novel-attempt-true-tactile-touchscreen-tech

[92] http://www.microsoft.com/surface/en-US

[93] http://pbinterfaces.com/Pacinian---Haptic-Touch-Technology.php

[94] http://www.immersion.com/products/touchsense-tactile-feedback/

[95] M. Rock, New Touch Screens Allow Blind to Read Braille, July 2011 http://www.mobiledia.com/news/97666.html

[96] http://www.open.ac.uk/disability/

[97] Stanford University, Stanford Engineering's New Online Classes: Hugely Popular and Bursting With Activity, October 2011 http://cacm.acm.org/news/137522-stanford-engineeringsnew-online-classes-hugely-popular-and-bursting-withactivity/fulltext

[98] MIT News Office, MIT launches online learning initiative, December 2011, http://web.mit.edu/newsoffice/2011/mitxeducation-initiative-1219.html

[99] https://www.anybots.com/\#front

[100] http://www.vgocom.com/

[101] http://www.vipi-project.eu/2011/02/launch-of-virgin-a-virtualportal-for-impaired-groups-interaction/

[102] http://www.etna-project.eu/

[103] http://www.atis4all.eu/

[104] http://www.aaate.net/

[105] http://www.fastuk.org/home.php

[106] http://hmi.dk/page2266.aspx

[107] http://qef.org.uk/our-services/

[108] http://www.i2home.org/

[109] G. Adams-Spink, EU smart-home concept shown off, February 2010 http://news.bbc.co.uk/2/hi/8495479.stm

[110]G. Dewsbury, Smart Home Technology for Disabled People, Hidden Wires, January 2010.

[111]G. Dewsbury, Smart Homes for Disabled People in the UK, HometoyseMagazine, June 2009.

[112] http://www01.ibm.com/software/solutions/soa/innov8/cityone/index.html

[113] http://www.floodsim.com/

[114] http://www.peacemakergame.com/
[115] http://www.aforcemorepowerful.org/game/index.php

[116] http://www.microsoft.com/games/flightsimulatorx/

[117] http://goal-net.eu/

[118] http://goet-project.eu/

[119] http://recall-project.eu/

[120] http://www.arts.rpi.edu/ ruiz/capAbilityGamesOverview_files/ca pAbilityGamesOverview.htm

[121] http://platform-online.net/2010/02/interview-david-brown-pennystanden/

[122] Adamo-Villani, N., Carpenter, E., Arns, L. (2006). 3D Sign Language Mathematics in Immersive Environment. Proceedings of ASM 2006 - 15th International Conference on Applied Simulation and Modeling, Rhodes, Greece, pp. 382-388.

[123] http://www.lumosity.com/

[124]E. Harrell, Study: Brain Exercises Don't Improve Cognition, April 2010http://www.time.com/time/health/article/0,8599,1983306,00. $\underline{\mathrm{html}}$

[125]D. O'Brien, Brain Training Games for Seniors: Looking for the best brain training app, February 2011 http://www.sharpbrains.com/blog/2011/02/10/brain-traininggames-for-seniors-looking-for-the-best-brain-training-app/

[126] http://en.wikipedia.org/wiki/Action_research

[127] http://en.wikipedia.org/wiki/Participatory_action research

[128]A field is born, July 2008, Harvard Business Review http://hbr.org/2008/07/a-field-is-born/ar/1

[129] http://en.wikipedia.org/wiki/Hawthorne effect

[130]R. Hess, Why Education Innovation Tends to Crash and Burn, December 2011, http://blogs.edweek.org/edweek/rick_hess_straight up/2011/12/w hy education innovation tends to crash and burn.html

[131]R. Slavin, How Education Innovation Can Thrive at Scale, December 2011 http://blogs.edweek.org/edweek/sputnik/2011/12/how education_i nnovation_can thrive at scale.html?cmp=ENL-EU-VIEWS2

[132] http://www.imsglobal.org/accessibility/accmdv1p0/imsaccmd ovi ewv1p0.html

\section{AUTHORS}

Charalampos Karagiannidis is an Associate Professor at the Department of Special Education, University of Thessaly, Greece (karagian@uth.gr).

Christos Kouroupetroglou is a Research Consultant at ALTEC S.A., Greece (chris.kourou@altec.gr).

Adamantios Koumpis is the Director of the Research Programmes Division, ALTEC S.A., Greece (akou@altec.gr).

This work was supported in part by the European Commission, DG Information Society and Media, ICT addressing societal challenges, ICT for Inclusion (SMART 2010/0077). Submitted, 27 June 2012. Published as resubmitted by the authors on 3 December 2012 . 